\title{
LAS COMUNIDADES PRIMARIAS Y EL LIBRE DESARROLLO DE LA PERSONALIDAD
}

\author{
Rubén Ortega Cotarelo \\ (Centro Universitario ESTEMA, Valencia)
}

\section{Libertad y comunidad}

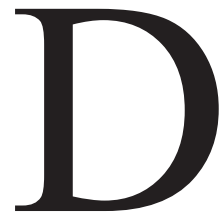

esde los años setenta la reflexión filosófico-política ha recuperado un papel de relevancia en el ámbito académico saliendo así de la marginalidad a la que había sido relegada durante años. Esta recuperación ha sido favorecida por la conocida controversia entre liberales y comunitaristas cuyas propuestas, réplicas y contrapropuestas han contribuido enormemente al enriquecimiento de los debates contemporáneos de filosofía política.

Sin duda, uno de los asuntos de mayor fricción entre ambas tradiciones ha sido la discusión sobre el lugar que debe otorgarse a la libertad de los individuos y el papel que la comunidad está llamada a desempeñar en las vidas de los ciudadanos.

Precisamente, la última obra de MacIntyre, Dependent Rational Animals ${ }^{1}$, trata este asunto desde una perspectiva distinta a la que suele ser habitual aportándonos sugerencias valiosas desde la antropología filosófica.

Aunque desde hace años Alasdair MacIntyre es conocido como un agudo crítico del liberalismo, considero que es incorrecto etiquetarlo como "comunitarista" a menos que se entienda que todo pensador crítico con el liberalismo es, por defecto, un pensador comunitarista.

Ciertamente su pensamiento presenta amplios puntos de conexión con esta corriente y una coincidencia manifiesta con sus críticas al liberalismo. Incluso algunos autores comunitaristas reconocen la influencia de MacIntyre en sus ideas. Pero creo que su aportación al debate político actual trasciende estas categorizaciones debido a que parte de un contexto de discusión filosóficamente más primario en el cual tienen incidencia decisiva las reflexiones

${ }^{1}$ MACINTYRE, A.: Dependent Rational Animals, London, Duckworth, 1999 (Animales racionales y dependientes, Barcelona, Paidós, 2001, trad. Martínez de Murguía, Beatriz). 
epistemológicas y éticas. Como trataré de mostrar posteriormente, lo que separa a MacIntyre de los liberales es tanto como lo que le separa de los comunitaristas, llegando a coincidir con los pensadores liberales en muchas de sus conclusiones aunque generalmente a partir de una argumentación y desde unos presupuestos muy diferentes.

MacIntyre es ampliamente reconocido como uno de los más importantes filósofos actuales de habla inglesa. Su trayectoria académica se ha desarrollado casi íntegramente en los Estados Unidos, donde ha participado en la mayoría de las disputas filosóficas del ámbito anglosajón.

Desde comienzos de los ochenta, ha publicado tres libros fundamentales de filosofía moral y política: Tras la virtud, Justicia y racionalidad, Tres versiones rivales de la ética, junto con numerosos y polémicos artículos. Tomados en su conjunto, constituyen un ambicioso intento de criticar las enfermedades de la modernidad, incluyendo la filosofía moral y política.

Tras la virtud, publicado en $1981^{2}$, sorprendió al mundo filosófico por el diagnóstico crítico hacia la moralidad moderna en general; en concreto, su crítica a lo que él llamó "el proyecto ilustrado". Esta obra comenzaba con una sugerencia inquietante; la moralidad de la modernidad está en un estado de grave desorden. Pero lo relevante es que carecemos de recursos para reconocer la amplia extensión de ese caos y para desenredarnos de él. Los desacuerdos contemporáneos sobre la justicia de las guerras, la aceptabilidad del aborto, los límites de la libertad o de nuestros pretendidos derechos no son sino ejemplos de conflictos sociales que nos parecen irresolubles.

El problema que se destacaba no es tanto el hecho de que seamos incapaces de ponernos de acuerdo sobre estos temas sino el hecho de que ni siquiera estamos de acuerdo en los criterios que debe cumplir una respuesta satisfactoria a estos desacuerdos. Tras la virtud es la historia de cómo vinimos a caer en este paradójico estado, cómo todavía continuamos engañados, y cómo podemos superarlo.

En Justicia y racionalidad $^{3}$ se realizaba un repaso histórico de algunas de las tradiciones de pensamiento moral y político más significativas con el fin de mostrar un camino racional para solucionar las interminables disputas que caracterizan a nuestras sociedades. La principal aportación es la idea -contraria al sentir dominante- de que no hay ninguna justicia en sí; ningún juicio sobre la justicia que no haga referencia a un modelo de

\footnotetext{
${ }^{2}$ MACINTYRE, A.: After Virtue, University of Notre Dame Press., (Indiana, USA), 1984 (Tras la virtud, Barcelona, Crítica, 1987, trad. Valcárcel, Amelia).

${ }^{3}$ MACINTYRE, A.: Whose Justice? Which Rationality, London, Duckworth, 1988 (Justicia y racionalidad, Barcelona, EIUNSA, 1994, trad. Sisón Alejo, G.).
} 
racionalidad práctica. $\mathrm{Y}$, del mismo modo, tampoco puede existir ningún modelo de racionalidad práctica que no se encuentre inserto en el seno de una tradición. La racionalidad práctica se desarrolla siempre dentro de una concreta y específica tradición política; es en el interior de las tradiciones donde se producen los conflictos y se proponen las revisiones que permiten el progreso racional.

En escritos posteriores ha profundizado en estas ideas tratando de mostrar que la existencia de inconmensurabilidad entre sistemas teóricos opuestos, puede, sin embargo, ser compatible con el debate racional. Además, ese debate puede ser el prólogo del tipo de debate en el cual alguna posición puede evidenciarse como racionalmente superior ${ }^{4}$.

Los recientes trabajos de MacIntyre mantienen la dimensión crítica y el profundo desencanto con la modernidad y con el proyecto ilustrado que la fundamenta. Sin embargo, sus controvertidas propuestas introducen una apuesta por la racionalidad de los debates políticos y por el pluralismo social a partir de la tradición aristotélico-tomista en la que se sitúa.

\section{El hombre como ser "endeudado"}

Las dos preguntas fundamentales que se abordan en Dependent Rational Animals última obra de MacIntyre, son: ipor qué es importante estudiar y entender lo que el ser humano tiene en común con miembros de otras especies humanas inteligentes? y ipor qué es importante que los filósofos de la moral estudien la vulnerabilidad y la discapacidad humanas?

Resolver estos interrogantes adecuadamente resulta de importancia esencial. Ninguno de ellos ha recibido especial atención por parte de la filosofía moral y política. De hecho, en esta obra el propio autor ha corregido algunas de sus investigaciones anteriores, en concreto, asume que estaba equivocado al suponer que era posible justificar una ética independientemente de las enseñanzas procedentes de la biología. Precisamente por ello, considera imprescindible estudiar cómo es posible la vida moral para seres constituidos biológicamente como el ser humano.

Estas ideas nos empujan a reflexionar sobre la condición animal del ser humano y la necesidad de reconocer la vulnerabilidad y la dependencia que resultan de ellas. El ser humano padece multitud de aflicciones desde su infancia hasta la ancianidad. Debido a su condición animal y, pese a las grandes diferencias, se comporta en relación con el mundo de una manera

${ }^{4}$ MACINTYRE, A.: Tres versiones rivales de la ética, Madrid, Rialp, 1992, pp. 100 y ss. trad. De Rovira, Rogelio (Three Rival Versions of Moral Inquiry, Notre Dame (Indiana, USA), University of Notre Dame Press., 1990). 
muy similar al resto de animales inteligentes. De hecho, no se separa nunca enteramente de lo que tiene en común con ellos.

Una de las conclusiones más relevantes que se derivan de ello es que las capacidades que permiten desarrollar al ser humano como un ser racional independiente, es decir, como ser autónomo, sólo pueden ejercerse adecuadamente cuando se reconoce su dependencia estructural de los demás. Si esto no se comprende, tampoco podrán apreciarse con claridad ciertos rasgos de su comportamiento como ser racional. Como afirma el autor: "el reconocimiento de la dependencia es la clave para la independencia"5.

Conviene destacar que en el fondo de estas ideas late una concepción de la persona como animal que se desarrolla a partir de las relaciones en las que se incardina. Por ello, los grupos en los que se integra no le resultan ajenos, sino que contribuyen a forjar su propia identidad, y son elemento esencial para su desarrollo individual.

Muchos de los bienes individuales y comunes son bienes compartidos, de modo que la decisión sobre la importancia que deben tener en la vida de un individuo determinados bienes no puede ser independiente de las decisiones que se tomen sobre la importancia de esos bienes para la vida de la comunidad. Del mismo modo, la diversidad de posibilidades abiertas para la vida de cualquiera está determinada por las decisiones políticas acerca de lo que es prioritario para la vida de la comunidad. Por eso, todo razonador práctico es, a la vez, un razonador político.

Charles Taylor también ha destacado la trascendencia de los vínculos interpersonales en el desarrollo de las personas y en la propia configuración de aquello que aprecian como valioso para sus propias vidas. Considera que nuestra comprensión de las cosas buenas e importantes de la vida puede transformarse por medio de nuestro disfrute en común con las personas que amamos y que algunos bienes sólo se nos hacen accesibles por medio de ese disfrute común ${ }^{6}$.

Las ideas que expone MacIntyre nos permiten afrontar con más rigor algunas aporías que la concepción individualista de la persona ha generado en el pensamiento liberal dominante. Recuperar una concepción del ser humano como ser estructuralmente dependiente y endeudado con los demás permite, a mi juicio, entender más adecuadamente nuestras relaciones interpersonales y configurar nuestras sociedades desde criterios de auténtica justicia.

\footnotetext{
${ }^{5}$ MACINTYRE, A.: Animales racionales y ..., cit., p. 103.

${ }^{6}$ Cfr. TAYLOR, CH.: Fuentes del yo. La construcción de la identidad moderna, Barcelona, Paidós, 1966, pp. 64 y ss.
} 


\section{El Estado no es el lugar de la comunidad}

MacIntyre ha sido muy criticado desde posturas liberales que consideraban que sus ideas implicaban una vuelta a estructuras sociales premodernas. Desde esa perspectiva, se le presentaba como un autor conservador cuyas propuestas regresivas negaban el pluralismo, la tolerancia así como otros valores universales conquistados por la modernidad ${ }^{7}$. A mi juicio, tales acusaciones resultan infundadas o provienen de una lectura descontextualizada de sus escritos. Estas interpretaciones no han tenido en cuenta el afán último que mueve estas propuestas y han extrapolado indebidamente al plano político ideas que pertenecen exclusivamente al plano de la ética.

Ciertamente, algunos autores contemporáneos tildados de "comunitaristas", y animados por el deseo de recuperar el protagonismo de los ciudadanos en la vida pública, han tratado de trasladar las nociones y los esquemas centrales de la polis griega a las sociedades actuales, con el propósito de recuperar la sensibilidad participativa que se echa de menos en muchas de nuestras democracias.

La polis representa una sociedad cuyos miembros han estructurado su vida en común para sostener formas de vida nobles y excelentes. La constitución de cada polis se podía entender, en consecuencia, como la expresión de un conjunto de principios acerca de cómo han de ordenarse los distintos bienes de la vida. El bien para los seres humanos sería el modo de vida que es mejor para ellos y expresa aquello en que consiste el desarrollo humano.

Pero la diferencia entre la comunidad política tal y como la entendió Aristóteles y los modernos Estados es demasiado grande. Las polis griegas eran sociedades de pequeña escala donde se compartía una cosmovisión y existían presupuestos acerca de la naturaleza y del bien común. Recuperar este tipo de comunidad en el contexto de nuestras democracias occidentales está condenado al fracaso. Precisamente porque nuestros Estados actuales lejos de configurar ese tipo de comunidad, son más bien conjuntos de instituciones grandes, complejas y destartaladas que combinan de forma incoherente el ethos de una gran empresa con continuas apelaciones a altos valores tales como la justicia o la libertad ${ }^{8}$.

En este punto, entendemos que MacIntyre está mucho más cerca de los planteamientos liberales que de los comunitaristas. Hace no mucho afirmaba: "los comunitaristas contemporáneos de los cuales me he distanciado, cuando

\footnotetext{
${ }^{7}$ Cfr. LAPORTA, F.J.: “Comunitarismo y nacionalismo”, Doxa: Cuadernos de Filosofía del Derecho, pp. 17 y ss., 1995.

${ }^{8}$ Cfr. MACINTYRE, A.: Animales racionales y dependientes, cit., p. 156.
} 
he tenido ocasión para ello, presentan sus propuestas como una contribución a la política de los Estados. Donde los liberales han insistido característicamente que el Gobierno del Estado debía permanecer neutral entre concepciones rivales del bien humano, los comunitaristas contemporáneos han afirmado que tal gobierno debería ser expresión de alguna visión compartida del bien humano, una visión que definiera un tipo determinado de comunidad. Donde los liberales han defendido característicamente que esa visión compartida del bien debería ser articulada en las asociaciones civiles voluntarias, los comunitaristas han insistido en que la nación debería ser constituida como una comunidad a través de las instituciones del estado nacional" ${ }^{\text {"Y }}$ Y concluye diciendo que desde su punto de vista, "los comunitaristas han atacado a los liberales en un tema en que los liberales están en lo cierto"10.

Reconocer la dimensión comunitaria de nuestras vidas es crucial pero esa dimensión no puede ser suplida por los Estados tal y como se configuran en la actualidad. Nuestros Estados contemporáneos nos proveen de algunos bienes públicos necesarios y establecen un ámbito de libertad y de seguridad apreciable, pero no debemos olvidar que los bienes públicos del Estado moderno no son los bienes comunes de una auténtica comunidad ${ }^{11}$. Por ello, afirma: "el Estado nacional no es y no puede ser el lugar de la comunidad"12. Y en una entrevista realizada hace unos años señalaba: "yo no soy un comunitarista. Yo no creo en ideales de formas de comunidad como remedio para los males sociales contemporáneos"13.

Constant, en La libertad de los antiguos y la libertad de los modernos, ya nos ponía en alerta respecto a la tentación de reinstaurar políticas cuyas virtualidades se perderían en caso de establecerse en situaciones ajenas a su contexto originario. Aquella era una visión romántica de las naciones concebidas como comunidades actuales o potenciales cuya unidad podía ser expresada a través de las instituciones del Estado. Y, como afirma MacIntyre, "la confusión de esta visión romántica con la concepción aristotélica llevó a muchos pensadores alemanes a establecer justo esa visión del Estado nacional como una comunidad omniabarcante, a la que los liberales se han resistido con razón porque entendían que genera totalitarismo"14.

\footnotetext{
${ }^{9}$ HORTON, J. \& MENDUS, S.: After MacIntyre. Critical perspectives on the Work of Alasdair MacIntyre, Cambridge, Blackwell, Polity Press, 1994, p. 303.

${ }^{10}$ Ibidem., p. 303.

${ }^{11}$ Cfr. MACINTYRE, A.: Animales racionales y dependientes, cit., p. 103.

${ }^{12}$ HORTON, J. \& MENDUS, S.: After MacIntyre. Critical perspectives..., cit., pp. 303 y ss.

${ }^{13}$ MACINTYRE, A.: "Nietzsche or Aristotle?", en BORRADORI, G.: American Philosophers. Conversations with Quine, Davidson, Putnam, Nozick, Danto, Rorty, Cavell, MacIntyre and Kuhn. Chicago, University of Chicago Press, 1994, p. 151.

${ }^{14}$ HORTON, J. \& MENDUS, S.: After MacIntyre. Critical perspectives..., cit., p. 303.
} 
Coincido con MacIntyre cuando señala que con mucha frecuencia cuando el Estado se considera a sí mismo como el encargado de conseguir el bien común de esta naturaleza, el resultado suele ser absurdo o desastroso y frecuentemente enmascara un tipo de manipulación de nuestras vidas. Su propia dinámica estructural termina invadiendo la esfera civil, y acaba imponiendo su lógica al resto de relaciones sociales.

Resulta paradójico que lo producido -la organización política, el Estadose haya convertido en la realidad invasiva, en el mayor peligro para la vida y la plenitud de los seres humanos, como ya adelantó Ortega en La rebelión de las masas. Parece que, a modo de profecía, se han cumplido muchos de los pronósticos que vaticinó en esa obra y, en lo que nos ocupa ahora, aquel que presentía una sociedad cuyas vitalidades ciudadanas se encuentran atenuadas y homogeneizadas.

Por estas razones MacIntyre no asume la perspectiva comunitarista. A su juicio, "el error comunitarista" 15 consiste en pretender infundir a la política del Estado los valores y mecanismos de participación propios de las pequeñas comunidades. Si analizamos la realidad social observamos como nuestros Estados se encuentran regidos por acuerdos entre una diversidad de intereses económicos y sociales en conflicto unos con otros. Si observamos adecuadamente, descubrimos que el peso que se concede a cada uno de esos intereses viene determinado por el poder de negociación político y económico y la capacidad que se tenga para hacer valer las propias opiniones en las mesas de negociación política. La capacidad económica tiene especial relevancia para adquirir poder político ya que implica acceso a recursos electorales, a los medios de comunicación y a relaciones con grandes empresas.

El poder lo tienen entonces los que son capaces de determinar cuáles serán las alternativas disponibles entre las opciones que hay: "el consumidor, el votante y el individuo en general tienen el derecho de expresar sus preferencias hacia una o más de las alternativas que se ofrecen, pero la gama de alternativas posibles, así como su presentación, es controlada por una élite" ${ }^{16}$. Las élites que gobiernan están obligadas, por tanto, a valorar mucho la competencia en la presentación persuasiva de las alternativas, es decir, en las artes cosméticas. MacIntyre los llama "professional manipulators of mass opinion" ${ }^{17}$.

Cuando las decisiones las toma una élite que domina el lenguaje y los conocimientos técnicos, los ciudadanos corrientes tienden a rechazar esa racionalidad y se genera una retórica de la manipulación y la persuasión en

\footnotetext{
${ }^{15}$ MACINTYRE, A.: Animales racionales y dependientes, cit., p. 177.

${ }^{16}$ MACINTYRE, A.: Justicia y..., cit., p. 328.

${ }^{17}$ Ibidem., p. 328.
} 
los foros de vida pública ${ }^{18}$. Además, para entrar con éxito en las áreas de la política se requieren recursos económicos que sólo el capitalismo puede suplir; recursos que aseguran a cambio acceso privilegiado a aquellos capaces de influir en las decisiones políticas. De este modo, como también señala Hoffe, se excluye a la mayoría de la gente de la posibilidad de participación activa y racional para determinar la forma de la comunidad en la que viven ${ }^{19}$. El resultado es que la mayoría disfrutamos de bienes públicos pero la distribución de bienes que realiza el Gobierno no refleja la opinión general alcanzada por medio de una "deliberación común regida por normas de indagación racional" ${ }^{\prime 20}$.

Horkheimer y Adorno han constatado que el desencantamiento del mundo moderno expresa el desencantamiento de la razón relegada a su función meramente instrumental. En coherencia con ello, han señalado que la gran mayoría de nuestros contemporáneos se piensan de entrada como consumidores, después como trabajadores y, sólo finalmente, como ciudadanos. En una sociedad así informada, la democracia tiende inevitablemente a convertirse en el ideal político dominante, mientras que las oligarquías de todo tipo se convierten irremisiblemente en la realidad política vigente ${ }^{21}$.

\section{El desarrollo de las comunidades civiles}

En el pensamiento de MacIntyre se da prioridad a la sociedad civil al entenderla como un fenómeno anterior al Estado, que no es más que una forma particular e históricamente condicionada de su organización política. El hecho de que el poder se haya ido concentrando progresivamente en las entidades estatales no ha hecho sino oscurecer esta prioridad de la vida ciudadana respecto a su estructuración jurídica. De forma coherente, se entiende que capacitar al Estado, incluso al Estado liberal, como baluarte de los valores, siempre pone en peligro esos valores, porque siempre existe el peligro de su manipulación, y el riesgo adelantado por Tocqueville de someter a las personas y a las comunidades a un poder tutelar omnipresente que vino a denominar "despotismo blando"22.

\footnotetext{
${ }^{18}$ MACINTYRE, A.: Tres versiones rivales..., cit., p. 213.

${ }^{19}$ Cfr. HOFFE, O.: "Pluralismo y tolerancia: acerca de la legitimación de dos condiciones de la modernidad", en Estudios sobre teoría del Derecho y justicia, Barcelona, Alfa, 1988.

${ }^{20}$ Cfr. MACINTYRE, A.: Animales racionales y dependientes, cit., p. 157.

${ }^{21}$ Cfr. MACINTYRE, A.: Marxism and Cristianity, Londres, Duckworth, $2^{\mathrm{a}}$ ed. 1995, p. xxvi. para apreciar las coincidencias de planteamiento.

${ }^{22}$ Cfr. TOCQUEVILLE, A.: La democracia en América, Madrid, Alianza, 1984, pp. 102 y ss.
} 
La conclusión de After Virtue fue una defensa de la "comunidad civil" y no del poder del Estado. Precisamente porque los modos de práctica social a pequeña escala y las comunidades locales establecen un ámbito que posibilita formas de vida en las que los ciudadanos pueden perseguir sus propios bienes racionalmente y de forma compartida. Ése es el contexto adecuado que permite la existencia de relaciones sociales informadas por apelaciones comunes a bienes internos a las prácticas de la comunidad. En consecuencia, debemos asumir una política involucrada en la construcción y sostenimiento de comunidades locales de pequeña escala, al nivel de la familia, el vecindario, el lugar de trabajo, la parroquia, la escuela o la clínica ${ }^{23 .}$

Gracias a los cuerpos y asociaciones intermedios de la sociedad los ciudadanos pueden, en el libre juego del pluralismo y por medio del diálogo racional, elegir y vivir sus propias concepciones acerca de lo bueno. Sólo a partir de comunidades más pequeñas es posible establecer espacios públicos donde se puedan encarnar las teorías en prácticas que informen las vidas de las personas. En estas esferas encontraremos la oportunidad de realizar lo que habitualmente se niega en los foros a gran escala que no poseen las condiciones necesarias para el debate racional público.

En definitiva, estas propuestas nos animan a la tarea de reconstruir un conjunto de diferentes instituciones no gubernamentales con la suficiente fuerza como para contrarrestar al Estado y, aunque no impida a éste cumplir con su función, puede, no obstante, evitar que domine y atomice el resto de la sociedad. Gellner afirma que el pluralismo político, en términos de unidades independientes y autónomas, ha sido frecuentemente dejado de lado porque las unidades locales carecen simplemente del poder necesario ${ }^{24}$.

Recientemente, Walzer ha reivindicado ideas similares tras constatar el surgimiento de una nueva ciudadanía reflexiva apoyada en lo que llama “asociacionismo crítico". Esta nueva ciudadanía consiste en la participación activa en las diferentes asociaciones que constituyen la sociedad ${ }^{25}$. Por medio de ellas es posible dar forma concreta a ideales y valores; lo que de otro modo serían acciones aisladas se transforman entonces en acciones con estabilidad. La vida interna de la sociedad se facilita en ellas, ya que sirven para encauzar propósitos compartidos, y posibilitan que se pueda participar en su realización.

Sin embargo, como bien han puesto de relieve muchos pensadores liberales, las comunidades también pueden convertirse en obstáculo para el desarrollo de las personas. Y en este punto MacIntyre coincide plenamente

\footnotetext{
${ }^{23}$ Cfr. Animales racionales y dependientes, cit., p. 151.

${ }^{24}$ GELLNER, E: Condiciones para la libertad: la sociedad civil y sus rivales, Barcelona, Paidós, 1996, p.73.
} 
con los liberales y critica a aquellos comunitaristas que presuponen la existencia de algo bueno en las comunidades como tales. A su juicio, éstas son propensas a corromperse por su estrechez de miras, la complacencia y el prejuicio contra los extraños cuando falta el reconocimiento de la dependencia mutua. Por ello, siempre debemos tener en cuenta que, incluso en el mejor de los casos, el ejercicio colectivo de la racionalidad deliberativa es siempre imperfecto lo cual implica una constante apertura a la superación, corrección y mejora ${ }^{26}$.

\section{Solidaridad y ciudadanía responsable}

Como hemos visto, la perspectiva de MacIntyre nos invita a entender a los ciudadanos como miembros unidos por lazos de pertenencia que reconocen la capacidad que tienen los demás para aportar al bien de la colectividad.

Una verdadera comunidad política existe para establecer un tipo de razonamiento cooperativo sobre fines comunes que evite su fragmentación y permita jerarquizar los diversos bienes que se persiguen en la vida. La comunidad política no existe sólo para ajustar intereses en conflicto o para proveer bienes y servicios; existe para hacer posible el tipo de comunidad en la que la deliberación conjunta sobre la vida pueda tener lugar dentro de un contexto de endeudamiento recíproco y justa solidaridad.

Desde esta perspectiva, es decir, desde de un discurso no individualista, es posible fundamentar actuaciones de los poderes públicos en beneficio de ciudadanos necesitados. Y podemos afirmar coherentemente que las sociedades deben evitar las situaciones de marginación porque de lo contrario se impide que cada uno pueda participar efectivamente en la construcción de la sociedad y en el disfrute de los bienes comunes que ésta propugna. Lo que legitima las políticas de justicia social es el interés de la comunidad, pero es un interés que coincide con el interés de cada uno ${ }^{27}$.

Como también Charles Taylor nos advierte, es erróneo concebir los derechos sociales como autoposesión desvinculada de las funciones y responsabilidades. Más bien son condiciones para la participación en una tarea común; son condiciones para una auténtica autonomía que se realiza al participar en la configuración colectiva ${ }^{28}$. Las políticas distributivas no se conci-

${ }^{25}$ WALZER, M.: "The Civil Society argument", en C. Mouffe (ed.), Dimensions of Radical Democracy. Pluralism, Citizenship, Community, Londres/New York, Verso, 1992, pp. 12 y ss.

${ }^{26}$ Cfr. MACINTYRE, A.: Animales racionales y dependientes, cit., p.167.

${ }^{27}$ Cfr. MACINTYRE, A.: "Community, Law, and the Idiom and Rhetoric of Rights", Listening, 26 (1991) p. 34.

${ }^{28}$ TAYLOR, CH.: "La diversidad de bienes", en La Politica. Revista de estudios sobre el Estado y la sociedad. Paidós, 1 (1996), cit., pp. 65 y ss. 
ben entonces como una imposición de los débiles ni mera condescendencia de los más fuertes, sino exigencia derivada lógicamente de una comprensión de la vida social como proyecto común, en el que cada individuo es capaz de aportar lo mejor de sí a las causas compartidas.

Si no concebimos la sociedad como un tipo de "empresa cooperativa", no hay buenas razones para que el Estado deba hacer todo o no deba hacer nada. Sin esa concepción de la sociedad, la discusión sobre la solidaridad como ingrediente de la justicia degenera en debates sobre cómo optimizar eficazmente la inversión de los recursos públicos.

Frecuentemente, en los debates acerca de la solidaridad hay un aspecto de índole antropológica que suele pasar desapercibido. Estos debates se centran en ver quien la realiza más eficazmente. Pero, además de la eficacia, conviene no olvidar que una solidaridad monopolizada por el Estado anula la libre colaboración de los agentes en el bien general y los bienes personales que de ello se derivan.

Para recuperar esta faceta de la solidaridad, MacIntyre coincide con Rorty en que el lugar de la solidaridad no es el de la organización estatal; no es el Estado el encargado de perseguirla, sino que son los propios ciudadanos quienes deben recuperar el protagonismo en ese ámbito de acción social distinto del Estado ${ }^{29}$.

El peligro de sustraer al Estado la administración de lo social conlleva un nuevo riesgo que no es otro que su posible mercantilización. Para evitarlo, es necesario que las funciones sigan siendo, de algún modo, públicas, aunque sea la sociedad quien se encargue de ello; y hace falta un nuevo modo de entender la autonomía, definida no sólo negativamente como ausencia de coerción, sino como capacidad de involucrarse en tareas de índole superior.

Estas ideas no implican confiar al mercado competencias públicas, sino que tienden a fomentar la participación de la sociedad en la gestión de lo público. Como ha señalado Alejandro Llano en Humanismo cívico, parece conveniente compartir estas cargas con ese tejido de comunidades y asociaciones civiles que abren sus objetivos a causas comunes ${ }^{30}$. De este modo, se podrá construir un Estado social y democrático con auténtico contenido social y verdadera participación en su configuración; una sociedad en la que se recupere el valor intrínseco de la actividad cooperativa, y se fortalezcan los vínculos entre los propios ciudadanos en espacios comunes donde quepa auténtica solidaridad y justicia social.

\footnotetext{
${ }^{29}$ RORTY, R.: Objetivity, Relativism and Truth, Cambridge, 1991, pp. 21y ss.

${ }^{30}$ Cfr. LlANO, A.: Humanismo cívico, Barcelona, Ariel, 1999, p. 106.
} 
Como conclusión, señalamos cinco comentarios que nos ha suscitado el diálogo con MacIntyre:

(1) Como podemos apreciar, el nivel conceptual de discurso en el que nos situamos no es el estrictamente jurídico o político sino el plano cultural y social. La preocupación que anima las reflexiones de este autor es de índole marcadamente ética. En esa dirección se debe enmarcar la defensa de la "comunidad civil" y de los modos de práctica social a pequeña escala.

(2) Sus propuestas pueden servir como punto de partida para repensar críticamente el modo en que se han venido configurando nuestras sociedades occidentales hasta nuestros días y en qué medida sus condiciones estructurales desincentivan el diálogo público y generan una homogeneización de las vidas de los ciudadanos.

(3) MacIntyre ha defendido la necesidad de fortalecer las relaciones sociales institucionalizadas, precisamente porque en ellas se puedan apreciar las distintas formas de vida y conocer lo que aporta cada una para la realización de nuestra libertad. Su análisis presupone una aproximación nueva a la realidad social que implica la recuperación del protagonismo de los ciudadanos, pero no en su aislamiento sino en el contexto de lazos interpersonales.

(4) Sin embargo, la descripción que realiza de los Estados occidentales y de sus mecanismos decisorios me parece algo simplista y claramente influenciada por las prácticas y los modos de actuar de la política en los Estados Unidos. Ciertamente, las críticas del autor reflejan parte de los problemas e imperfecciones de nuestros sistemas democráticos pero, a mi juicio, centrarse exclusivamente en sus aspectos negativos le impide entrever todas sus virtualidades así como descubrir posibilidades ocultas de regeneración

(5) La deliberación sobre lo público en nuestras sociedades occidentales puede resultar muy enriquecida si los Estados contemporáneos reconocen la importancia de esas entidades en las que participa el ciudadano y articulan los cauces para facilitar su presencia efectiva. En definitiva, para aumentar la democratización de las instituciones, es preciso generar una libertad concertada activa y responsable; un pluralismo no impuesto desde arriba sino un pluralismo social ascendente. 